\title{
The Practice of Defining Markets A Comment on Charles W. Smith
}

\author{
Patrik Aspers
}

\section{Charles Smith in the Market}

It is with great pleasure that I take this opportunity to write a short comment based on Charles Smith's article, "Markets as Definitional Practices" (2007). This is also an opportunity to present and discuss how markets can be understood. Smith, as is known, has written many interesting texts (e.g., Smith 1981; 1989) that deal with markets, and the current one is no exception.

There are many things that I like with Smith's work. I agree that the market is the most central "institution" of the economy, that the larger aim of economic sociology is to develop a theory of markets, and that ethnography is an indispensable strategy in this undertaking. He should also be praised for addressing markets in relation to money, which is all too rare in economic sociology.

Moreover, Smith has, in a way that resembles Weber, combined hands on knowledge of financial markets with an analytic outlook. Max Weber wrote two pamphlets (Weber [1893-98] 1999) for the Library of Workers in Göttingen on Die Börse (the stock exchange), which show many sociological insights, but as he grew older, Weber further developed his sociological thinking (cf. Swedberg 2000). Smith's view on markets, if I may, has also become more sociological over time.

However, my comment is not, and should not be, merely a celebration of Smith's work; that would be to demean it, as well as the important issue being researched. The issue at stake, as I see it, is markets. I want to point out some issues of disagreement, or where I think one should go further or, in some cases, in a different direction. Before I discuss Smith's contribution I make a short summary of how I understand his arguments. 


\section{Summary of the Arguments}

Today few economic sociologists disagree with the central statement of Smith, that markets are part of society. Put in the parlance of economic sociology, markets are embedded, not only in other markets (White 2002), but in the social environment at large. This almost self-evident "insight" must be seen in the light of the differentiation of subsystem, in the words of Luhmann, or spheres, in the words of Nietzsche, Simmel, or Weber. These changes took place in the 17th and 18th century (cf. Luhmann [1984] 1995:461). Regardless of the concepts used, it is clear that the economy has become more "independent." Thus, though the economy has always been embedded, it has over time become less embedded.

The theoretical framework Smith develops aims to, "frame markets as evolving social practices in a wide range of more encompassing social practices" (2007:4). In Smith's text, markets are presented as social units, in which actors define themselves and their activities by generating shared meaning as a result of actors taking on each others' roles. This co-activity of market actors generates narratives of markets. A point made by Smith that he shares with Simmel, Weber, and Habermas, is that market activities, as Smith says, "spill over" to other parts of social life. What is meant hereby is not only the idea of market externalities, which economists as well as, more recently, Michel Callon (e.g. 1998) have addressed, but what is called "marketization," or the "logic of the market." This idea is common in economic sociology, and I do not think it is wrong, but it must be put in perspective. One should remember that also non-market activities spill over in markets. Markets, it has been shown, may also become more "ethical" (Aspers 2006). The literature suggests "flows" in both directions (Hirschman 1986:105-141), i.e., "to" and "from" the market economy.

\section{What is a Market?}

This is a straightforward question, and though $I$ agree with much of what is said in Smith's text on markets, I fail to see a definition or a description, which sets markets apart from other "social practices." I therefore propose the "following definition of a market: a social structure for exchange of rights, which enables people, firms and products to be evaluated and priced. This means that at least three actors are needed for a market to exist; at least one actor, on the one side of the market, who is aware of at least two actors on the other side whose offers can be evaluated in relation to each other (cf. Aspers 2005c:427). This definition can be seen as concentration of Weber's ([1921-22] 1978) and Simmel's ([1908] 1983) discussions of markets. An offer can be a price that a 
seller is willing to accept, or a price a buyer is willing to pay. There must be a way of calculating, or at least evaluating, the offers in relation to each other, which implies the crucial component of competition in markets. To evaluate offers, one does not need a currency, but at least money of accounts (Dodd 2005). This means that the task of relative evaluation can be accomplished with, for example, shells or the Euro. Formal or informal rights are exchanged in markets, and prices are means for economic evaluation of at least two competing offers.

Buyers and sellers have different interests, or as Geertz puts it, "under whatever skies, men prefer to buy cheap and sell dear" ([1978] 1992:226). Though markets originally were tied to a place (Swedberg 1994), often with a name, e.g., "Smithfield market," this need no longer be the case (cf. Knorr Cetina and Bruegger 2002). Due to differentiation of markets over time, contemporary markets are more often connected to products, e.g., the market for laptops. A market, in contrast to individual transactions, must have some stability over time. The extension in time that characterizes a market is both created by a narrative, and the condition of this very narrative, which Smith points out. The narrative is one cultural aspect of a market among others, including its name, the way to behave in the market, and place (if there is one). This indicates that markets may be different, though they in some cases trade identical products, such as stock exchanges, because, for example, the institutions, and more generally, the cultures, of the markets differ. A market, of course, shares many cultural dimensions with other markets and non markets, such as trust (cf. Möllering 2006).

The market definition above is general, but sociologists have identified kinds of markets (cf. Aspers 2005c). Economists have focused more on the perfect market presented by Knight (1921). This market and its deviant cousins (e.g., monopoly markets) are often conceptualized using the notion of good. The literature of different kinds of goods is too large to cover here, but Veblen, natural monopoly goods, Giffen, positional, and public goods, are some examples. The sociological approach, in contrast, stresses the market and social relations as the central objects of analysis.

Smith addresses an issue that the neoclassical approach takes for granted, namely the problem of definition of what is traded in markets, such as shoes, options, or cleaning services. This I see as the first coordination problem out of three that have to be solved in a market. The idea of coordination problems in market is discussed in detail by Jens Beckert (2007), though I here couch these "problems" in a slightly different way. The solution to this first problem is connected to the value of the market (cf. Faverreau, Biencourt and EymardDuvernay 2002), or "what the market is all about." Its solution diminishes the uncertainty of the market, and it contributes to the separation of markets from each other. The second coordination problem is "how do we do it here?" This 
refers to the culture of the market - and more concretely to the informal and formal institutions of the market. The third coordination problem, "how much is it worth?" is the determination of the economic value, usually in terms of price.

There are two kinds of solution to the coordination problems of the market, or, as it were, two forms of markets with different social structure, called standard and status (Aspers 2005b). Though I cannot deal with it here, these are also characterized by different "price setting" mechanisms. The two market forms are solutions to the problem of order that sociologists are interested in, which is a condition for the problem of efficiency that economists deal with. In a standard market the value - "what the market is all about" - is a more entrenched social construction (more taken for granted) than the social structure made up of the actors taking part in the market. Examples are markets for egg, crude oil and stock exchanges, in which there is a scale of quality (value) that can be used to evaluate the items traded. This evaluation can be made independently of the actors trading the items. The standard market structure also covers the cases of homogeneous products. A further way of describing a standard market is that what is valued and traded in it remains, though buyers and manufacturers can be exchanged, without substantially affecting the market.

The situation is reversed in a status market: what is valued and traded in a status market is less taken for granted than the social structure of actors trading. In a status market, actors, for example a set of garment producers and their ideal-type consumers ranked in two different but interconnected status hierarchies, remain unchanged - in relative time - compared with the items traded, i.e., fashion garments, which are subject to change. That is, though the value of the market remains, "fashion garments," its manifestation in products, change quickly, which means that one cannot predict the market based on the product. This can only be solved by interaction of market actors. When, for example, high status buyers ("celebrities") and sellers ("high status brands") come together they define what "fashion garments" is, but they also reinforce the social structure.

Both standard and status markets solve the coordination problems, and both generate a social structure and cohesion, though cohesion in status markets is around the actors, and in the standard market it is around the commodity (see Figure 1). However, "status" and "standard" are both social constructions, and refer to the relative entrenchment of value and social structure.

Much more can be said about what a market is, but as I see it, the market definition provided does not contradict what Smith talks of. It has, however, the advantage that it nails down what makes markets different from other "social practices." It seems to me that the option market is a standard market. This means that it does not matter from whom one is buying, or to whom one is selling, the product is what it is and can be exchanged for money. This market 
is of course embedded in other markets, for example the markets of information and the stock exchange market. It has culturally conditioned institutions, such as insider rules. I think that it is simply too early to tell if the word/phrase market that Smith discusses will be stabilized as a status or standard market, and it would be wrong of me to draw any conclusions, since I do not know enough about this market.

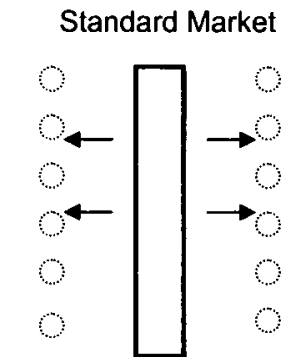

Buyer

Seller

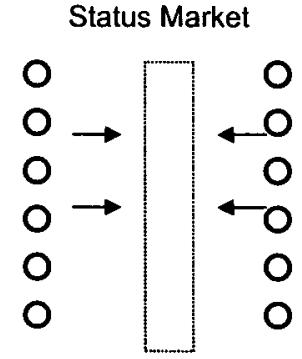

Buyer

Seller

Figure 1. The relation between value and structure in standard and status markets (idealtypes). The bold lines represent the strongest social construction in each of the markets, and the weakest are dotted. The arrows indicate the direction of valuation. This means that standard is a stronger social construction (more entrenched) than the rank orders of actors in a standard market.

\section{How do Markets Emerge?}

I have proposed a market definition, and argued that there are different kinds of markets. I have, however, not yet discussed the process which leads to the different kinds of markets outlined. We can, and should, describe the emergence of markets empirically, especially since this has not been done enough in the economic sociological literature. I outline two ideal-types of market emergence that can be used in empirical research. The first type, organized coordination, refers to a situation when actors come together, negotiate either directly, or indirectly, for example via the state or an industrial organization, and determine what the market is all about, it rules and so on (e.g., Fligstein 2001. Also stakeholders who feel affected, though they do not directly take part, may be involved in this process, and pursue their interests. This kind of market formation is common, and it often means that a newly founded market has been mapped on existing markets or that a theory is used as a blue-print of the market, which is to say that they are performed (cf. MacKenzie 2006).

I propose, following Simmel ([1922] 1955:147, 155-56) that collaboration among market members, or "members in being" is common. Thus, actors 
come together and decide the "rules of the game," i.e., the informal institutions of the market, and thus solve the second coordination problem. This may concern the rights of entrants, the size of the bundles of trade and so on. This, however, does not hinder fierce competition among markets actors at the level of price, marketing, product development, and so on. Organized coordination is a common way to construct markets, but I will not further comment on this kind of market formation, though one could probably model different phases of organized coordination.

The second ideal-type, noncoordinated organization, draws on the "order from noise" principle (cf. Luhmann ([1984] 1995), which means that a small trigger in a situation of "chaos" or non-order leads to the start of a social process from which eventually order may emerge. This process also creates the value of what the market is, as well as market actors' identities. Smith studies markets within capitalistic economies. I will also assume capitalism, and propose, in a much too short way to provide anything but an overview, how we may think about emergence and formation of markets, focusing on the order from noise principle.

The emergence process of markets is simultaneous with the generation of market actors. I propose that one can divide the spontaneous market formation, analytically, into three phases, Orientation, Contraction, and Cohesion. These phases are graphically illustrated in Figure 2. I will, because of the limited space, avoid some preliminary steps about the emergence of identities and communicative practices. As a starting point I assume a number of actors with agency and an interest in "exchange" the goods and services that they possess. These actors have cultural, social, and economic resources. In this market process, also the culture of the market, or for short, "this is how we do it here" emerges, which is the solution to the second coordination problem. Smith (2007:3) points to a number of kinds of rules that must be in place to talk of markets. Culture, more generally, is not only these formal rules that Smith stresses; informal rules of gossip, language, and appropriate dress can also make one market differ from another (cf. Preda 2005; Aspers 2005a; Geertz 1963). Below I briefly explain the three phases.

\section{Orientation}

This phase assumes, as indicated, interest in trading. Different actors begin to check each others' "offers" out. What is valued is typically up for grabs and not decided in the early phase of the market process, in which we can talk of "orientation among actors." Actors have different interests - in terms of what they want to trade and if they are interest in buying or selling - but their motives or "preferences" are also affected in this process of interaction; these have to be socially constructed and cannot be assumed. The partakers in the 
process orient more to those who show matching trading interests (i.e., both those who want to sell and those who want to buy "the same thing"). At this stage people cannot cognitively know of all other actors, nor what they want and know. Information is not free or easy to gain, since there is no central device that gathers information and transmits or sells it. Moreover, it is at this stage not clear what "market information" is.

Orientation

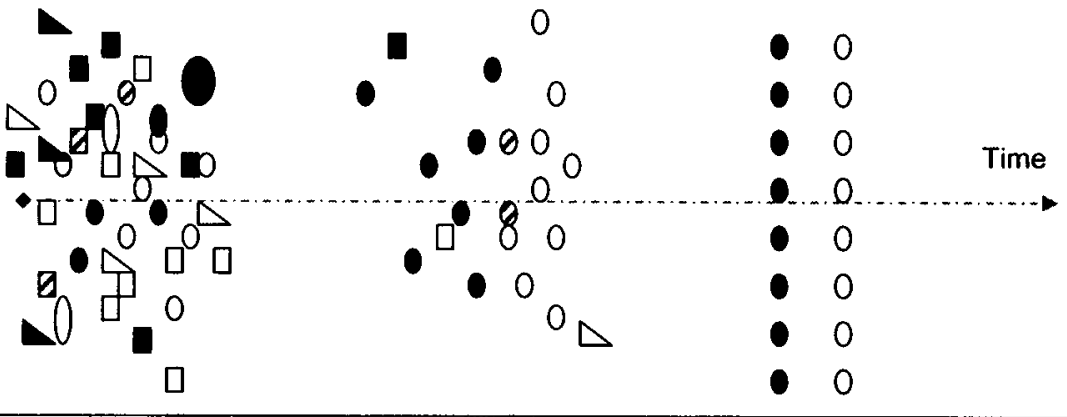

Figure 2. Actors in phases of market formation. Filled actors are sellers and non-filled are buyers. Striped actors are, yet, undecided if they are buyers or sellers. The different forms of the figures represent actors' different trading interests (different items). Only interests of three broadly defined items are illustrated here.

\section{Contraction}

The next phase of market development, which often is seen in relation to its environment made up of already existing markets, shows tendencies to contraction, when actors come together and begin to recognize what others want to trade. This is because those who have "deviant" interests, for example those who want to sell stamps or carpets, instead of the dominating interest in bikes, will drift away or become excluded in interactions, realizing that "this is not for me," since their deviants "offers" or interests are not relevant in this particular "preamble" of a market. One can here talk of contraction among those who have an interest in certain items over time. More and more things become taken for granted in social interaction of the actors; and one may see this as a preamble of culture. Some actors in this phase may still not be sure if they are selling or buying, but they will gradually be forced to make a decision if they want to trade, and thus become part of what is under construction, or stay outside of it. Market roles, as "traders" (cf. Geertz 1963) or "buyers" or "sellers" (cf. Aspers 2005a), as well as actors' identities in correlation to these roles are beginning to form at the same time as it becomes clearer what "the market" is all about. 


\section{Cohesion}

The final phase can be described with the notion of cohesion, which is to say that a market is developed and the social structure is coagulated; there is order in the market. From a social constructivist perspective, the market - and its components - are taken for granted. When a "market" reaches the phase of cohesion it may gain a name. In this phase both the first coordination problem of what the market is all about, but also the second, or "how we do it here," are solved. One may here talk of collective identities of the market actors (such as garment producers). Only with the completion of this phase can one speak of a market. That there is a market means that the uncertainty that actors have to cope with is diminished. From my understanding of Smith's description, the option market is mature and it is in the cohesion-phase, it is in the strictest sense a market. The "word/phrase" market is still in formation.

I agree with Smith that if one is to talk of consensus among market actors, they must interpret the market in largely the same way; if their expectations are not met at all, one cannot talk of order, and hence not of a market. Though prices is an issue in all phases, it is only in an ordered market that actors can focus more on price setting of what is traded. Order, as I have indicated, can rely on the value of what is traded in the market, i.e., the commodity or the service, or on the social structure. The two illustrations in Figure 1 shows the ideal-typical forms of market order, standard and status in the phase of cohesion. I have not discussed why the one rather the other emerges. This means that I have not provided an explanation.'

One should here, in relation to organized market coordination, add a dimension that Smith does not speak of, but which is of crucial importance when it comes to market analysis, namely competition between markets. One can even observe competition between market places, such as between different stock exchanges to attract stocks and investors, but also between markets that trade different items.

\section{Summary}

I learned much from reading Smith's text, and I think that his idea to study markets in a truly longitudinal design is the only empirically viable approach to understand market emergence. My first contribution is to provide a definition of markets, the second to outline types of market, and the final is to discuss how markets may emerge. One may, to conclude, say that economic

1 Powerful states and actors, especially if they are already operating in other markets, are likely to use their power to fashion markets. More generally, the more equal the actors are, and the less experience they have, the less likely it is that they will organize the coordination of the market. 
sociology is in the contraction phase when it comes to the coordination of our works on markets. This means, to paraphrase the above mentioned point of Simmel, that though we may not agree on everything, there is still a larger frame of collaboration among sociologists studying the economy.

\section{References}

Aspers, Patrik

2005a Markets in Fashion, A Phenomenological Approach. London: Routledge.

2005b Status and Standard Markets in the Global Fashion Industry. Cologne: MaxPlanck Institut für Gesellschaftsforschung, Discussion Paper 05/10.

2005c Markets, sociology of. In J. Beckert and M. Zafirovski, eds., International Encyclopedia of Economic Sociology. London: Routledge Ltd.

2006 Ethics in global garment market chains. In N. Stehr, C. Henning, and B. Weiler, eds., The Moralization of Markets. London: Transaction Press.

Beckert, Jens

2007 Die Soziale Ordnung von Märkte. Cologne: Max-Planck Institut für Gesellschaftsforschung, Discussion Paper 07/6.

Callon, Michel, ed.

1998 The Laws of the Market. Oxford: Blackwell Publishers

Dodd, Nigel

2005 Reinventing monies in Europe. Economy and Society 34(4):558-583.

Favereau, Olivier, Olivier Biencourt, and François Eymard-Duvernay

2002 Where do markets come from? From (quality) conventions! In O. Favereau and E. Lazega, eds., Conventions and Structures in Economic Organization: Markets, Networks and Hierarchies. edited by. Cheltenham: Edward Elgar.

Fligstein, Neil

2001 The Archtecture of Markets: An Economic Sociology for the Twenty-First Century Capitalist Societies. Princeton, NJ: Princeton University Press.

Geertz, Clifford

1963 Peddlers and Princes, Social Change and Economic Modernization in Two Indonesian Towns. Chicago: University of Chicago Press.

1992 [1978] The bazaar economy: Information and search in peasant marketing. In M. Granovetter and R. Swedberg, eds., The Sociology of Economic Life. Boulder: Westview Press.

Heidegger, Martin

2001 [1926] Sein und Zeit. Tübingen: Max Niemeyer Verlag.

Hirschman, Albert

1986 Rival Views of Market Society and Other Essays. New York: Elisabeth Sifton Books.

Knight, Frank

1921 Risk, Uncertainty and Profit. Boston: Houghton Mifflin Company. 
Knorr Cetina, Karin and Urs Bruegger

2002 Global microstructures: The virtual societies of financial markets. American Journal of Sociology 107(4):905-950.

Luhmann, Niklas

1995 [1984] Social Systems. Stanford. CA: Stanford University Press.

MacKenzie, Donald

2006 An Engine, Not a Camera: How Financial Models Shape Markets. Cambridge: Cambridge University Press.

Möllering, Guido

2006 Trust: Reason, Routine, Reflexivity. Oxford: Elsevier.

Preda, Alex

2005 Legitimacy and status groups in financial markets. The British Journal of Sociology 56(3):451-471.

Simmel, Georg

1983 [1908] Soziologie, Untersuchungen über die Formen der Vergesellschaftung, Georg Simmel Gesammelte Werke, 2. Berlin: Duncker und Humbold.

1955 [1922] The web of group-affiliation. In Conflict and The Web of Group-Affiliations. New York: The Free Press.

Smith, Charles

1981 The Mind of the Market: A Study of Stock Market Philosophies, Their Use, and Their Implication. Totowa: Rowman and Littlefield.

1989 Auctions: The Social Construction of Value. Berkeley: University of California Press.

2007 Markets as definitional practices. Canadian Journal of Sociology 32(1):1-39.

Swedberg, Richard

2000 Afterword: The Role of the Market in Max Weber's Work. Theory and Society 29(3):373-384.

1994 Markets as social structures. In N. Smelser and R. Swedberg, eds., Handbook of Economic Sociology. Princeton, NJ: Princeton University Press.

Weber, Max

1999 [1893-98] Max Weber Börsenwesen, Schriften und Reden 1893-1898, Max Weber Gesamtausgabe, 1/5 I. Halbband, Tübingen: J.C.B. Mohr.

1978 [1921-22] Economy and Society: An Outline of Interpretive Sociology, edited by G. Roth and C. Wittich. Berkeley: University of California Press.

White, Harrison

2002 Markets from Networks: Socioeconomic Models of Production. Princeton, NJ: Princeton University Press. 
Copyright of Canadian Journal of Sociology is the property of Canadian Journal of Sociology and its content may not be copied or emailed to multiple sites or posted to a listserv without the copyright holder's express written permission. However, users may print, download, or email articles for individual use. 